\title{
PARTIDOS E INDEPENDIENTES ANTE LA CONSTITUCIÓN: EL CASO DE LA DISTRIBUCIÓN DEL TIEMPO EN LA FRANJA ELECTORAL
}

\author{
Pablo Marshall Barberán*
}

\begin{abstract}
RESUMEN
El presente artículo presenta, a través de la exposición y análisis de una sentencia judicial, dos cuestiones relevantes de derecho constitucional. En primer lugar, se presenta el problema que supone la aplicación de la ley a un caso, cuando el resultado consecuente de dicha aplicación resulta inconstitucional. En segundo lugar, en un ejercicio interpretativo, se presentan los principios constitucionales que deberían orientar y regular la práctica del derecho electoral, en especial la forma en que debe distribuirse el tiempo de la franja electoral entre los distintos candidatos. La implementación de una concepción bien definida del principio de igual tratamiento entre independientes y partidos políticos es, quizás, lo más sustantivo del trabajo.
\end{abstract}

FRANJA ELECTORAL - PARTIDOS POLÍTICOS - IGUALDAD

\section{Political parties and independents before the constitution: the broadcast time allocation case}

\begin{abstract}
This work elaborates on two relevant issues in Constitutional Law, by means of analysing a recent judicial decision. The first of those issues relates to the difficulty that arises when the application of a statute to a specific case results in an infringement of the Constitution. The second topic refers to the constitutional principles that should guide and regulate the practice of Electoral Law, specially the manner in which broadcast time should be allocated between the various candidates. The main objective of this work is to set up a well defined conception of the principle of equal concern for political parties and independents.
\end{abstract}

FREE BROADCAST TIME - POLITICAL PARTIES - EQUALITY

* Abogado, profesor instructor, Facultad de Ciencias Jurídicas y Sociales, Universidad Austral de Chile, Valdivia, Chile. Pablo.marshall@gmail.com El autor agradece a Guillermo Jiménez, quien hiciera generosos comentarios a un borrador del presente artículo. Artículo recibido el 15 de marzo de 2008 y aceptado para su publicación por el Comité Editorial el 27 de mayo de 2008. 
$\mathrm{E}$ n el presente artículo se analiza la sentencia del Tribunal Calificador de Elecciones denominada Alianza Nacional de los Independientes con Consejo Nacional de Televisión. Esta sentencia falló la apelación de la resolución de dicho Consejo que fijó la distribución del tiempo de la franja electoral para las elecciones presidenciales y parlamentarias de diciembre del año 2005.

Se describirán las normas legales aplicables y los hechos del caso, para después hacer un programa del análisis del caso, que dé cuenta diferenciada de los problemas orgánicos e interpretativos del caso en análisis.

\section{LA FRANJA ELECTORAL Y EL SISTEMA DE DISTRIBUCIÓN DE TIEMPO}

\section{a) La franja en la Ley 18.700}

La franja electoral consiste en la destinación, por parte de todos los canales de televisión de libre recepción, de 20,30 o 40 minutos diarios para transmitir propaganda electoral previamente a las elecciones de Presidente de la República, de diputados y de senadores. También se utiliza en el caso de plebiscitos nacionales. La franja electoral está reglamentada en los artículos 31 y 31 bis de la Ley 18.700. El estatuto de la franja electoral que dichos artículos establecen puede describirse de la siguiente forma: (a) sólo está establecida para los medios de comunicación televisivos, excluyendo por tanto a los radiales y a la prensa escrita; (b) la franja electoral es gratuita, tanto para los candidatos como para el Estado. Esto en lo que respecta a la destinación del espacio de tiempo en que se transmite por parte de los canales, pues el contenido de cada propaganda debe ser proveído por cada candidato o partido; (c) la franja electoral es obligatoria para todos los canales de televisión de libre recepción del país, tanto estatales como privados; (d) la franja electoral es la única forma en que se puede realizar propaganda y publicidad a través de los canales de televisión de libre recepción. Además, a los canales de televisión que no sean de libre recepción (de pago) les está probibido hacer propaganda electoral, por lo que debe concluirse que la franja electoral es la única forma en que se puede realizar propaganda electoral por medio de la televisión, cualquiera sea su tipo; (e) la franja tiene normalmente una duración de 27 días, término que empieza a contarse 30 días antes y termina 3 días antes del día de la elección. En este sentido, la franja electoral sigue las reglas generales sobre la propaganda electoral (art. 30 Ley 18.700). Para el caso de la franja electoral previa al balotage, su duración es de 11 días, extendiéndose desde el decimocuarto hasta el tercer día antes de la elección, y (f) la duración de la franja es variable (20, 30 o 40 minutos). Será de 40 minutos cuando la elección sea conjunta de Presidente y de parlamentarios. Será de 30 minutos en los casos en que la elección presidencial o parlamentaria no sea conjunta. Será de 20 minutos en el caso del balotage de la elección presidencial. 


\section{b) Los criterios de distribución de la franja}

El órgano encargado de realizar la distribución de la franja entre los candidatos y partidos es el Consejo Nacional de Televisión, quien lo hará mediante un Acuerdo de su directorio, que deberá publicarse en el Diario Oficial. La franja electoral se distribuye siguiendo diversos criterios. La Ley señala cuáles son las reglas que debe seguir el Consejo para la distribución del tiempo de la franja entre los candidatos y los partidos. Para la elección presidencial el inciso $3^{\circ}$ del artículo 31 no presenta mayores problemas en la medida que establece una regla de distribución igualitaria entre todos los candidatos presidenciales:

Para las elecciones de Presidente de la República, los tiempos [...] corresponderán, en partes iguales, a cada uno de los candidatos. Para el caso previsto en el inciso segundo del artículo 26 de la Constitución Política [balotage], el tiempo será de diez minutos, distribuido también en partes iguales.

En el caso de las elecciones parlamentarias, la regla presenta una complejidad mucho mayor. Existen tres supuestos de tratamiento diferenciado. En primer lugar, está el caso de los partidos que participaron en la elección anterior, para ellos la ley establece un criterio estrictamente proporcional:

En las elecciones de diputados y senadores, a cada partido político corresponderá un tiempo proporcional a los votos obtenidos en la última elección de diputados (inc. $4^{\circ}$, primera parte).

En segundo lugar, para el caso de los partidos políticos nuevos, esto es, aquellos que no participaron de la elección anterior y que, por tanto, no se les puede aplicar la regla de la proporcionalidad derechamente, la ley establece una regla de equivalencia:

en caso de [los partidos] que no hubiere[n] participado en ella, tendrá[n] el mismo tiempo que le corresponda al partido político que hubiere obtenido menos votos (inc. $4^{\mathrm{o}}$, segunda parte).

En este caso, la regla de equivalencia es requisito para la aplicación de la regla de la proporcionalidad. En tercer lugar, para el mismo caso de diputados y senadores, pero ahora en relación a las candidaturas independientes, la ley sostiene nuevamente una regla de equivalencia como requisito de la regla de proporcionalidad. Sin embargo, incorpora una tercera regla, una regla de distribución igualitaria, igual que en el caso de los candidatos presidenciales:

Al conjunto de las candidaturas independientes corresponderá, asimismo, un tiempo equivalente al del partido político que hubiere obtenido menos sufragios en la última elección, el que se distribuirá entre ellas por iguales partes (inc. $5^{\circ}$ ). 
A continuación se reconstruirá la forma en que el Consejo realizó la distribución del tiempo, la reacción de quienes se sintieron perjudicados por su decisión y la solución que el Tribunal Calificador de Elecciones dio al asunto planteado.

\section{EL CASO}

\section{a) La resolución del Consejo Nacional de Televisión}

En el asunto que interesa, el Consejo ejerció su competencia de fijar el tiempo correspondiente a cada candidato y partido en las elecciones parlamentarias de acuerdo a las reglas de proporcionalidad, equivalencia e igual distribución del tiempo. El Consejo ajustó su decisión a los resultados electorales obtenidos por los partidos políticos en la elección inmediatamente anterior al proceso electoral en curso. El Consejo sostuvo que tomó en cuenta los siguientes criterios para realizar el cálculo antedicho:

a) No se consideran los votos nulos ni los votos blancos de la elección del dos mil uno;

b) No se consideran los votos obtenidos por los partidos políticos que participaron en estas elecciones, pero cuya inscripción posteriormente haya sido cancelada por el Servicio Electoral;

c) No se consideran los votos obtenidos por las candidaturas independientes en el año dos mil uno;

d) A los partidos que no participaron en la elección parlamentaria de dos mil uno se les asigna una votación igual a la del partido que participó en esas elecciones y obtuvo la menor cantidad de votos. El partido de referencia fue el Liberal;

e) Al total de candidaturas independientes inscritas se le asigna una proporción similar de votos a la obtenida por el partido menos votado en la elección de dos mil uno, luego ese tiempo se divide por el número de candidaturas independientes (parte expositiva).

La resolución del Consejo fijó, en consecuencia, el tiempo correspondiente a cada partido que no participó en la elección anterior en un segundo y para los candidatos independientes en conjunto estableció que debería distribuirse un segundo en partes iguales. $^{1}$

\section{b) La apelación a la resolución del Consejo}

Ante la decisión del Consejo, Ricardo Fernández, representando a la Alianza Nacional de los Independientes dedujo recurso de apelación respecto a la resolución arriba descrita ante el Tribunal Calificador de Elecciones, dado que tal resolución decía

\footnotetext{
${ }^{1}$ Acta de la sesión extraordinaria del Consejo del viernes 14 de octubre de 2005.
} 
"relación con la distribución del tiempo" asignado a los partidos políticos y candidatos electorales (inc. 3 art. 31 bis Ley 18700) y, por tanto, era de aquellas apelables. La apelación se fundó en que la resolución del Consejo, de asignar un segundo a cada uno de los partidos integrantes de la alianza recurrente, vulneraba el principio de igualdad ante la ley. Solicitaba el apelante que se ampliara "en conciencia" el tiempo de propaganda electoral por televisión que había sido asignado a su partido.

\section{c) El fallo del Tribunal Calificador de Elecciones}

El Tribunal Calificador de Elecciones soluciona la cuestión planteada de la siguiente manera:

Que confrontados los referidos resultados electorales con la operación efectuada por el Consejo Nacional de Televisión debe concluirse que la distribución del tiempo que, en este caso, ha realizado dicha institución, por el mandato expreso de la Ley [...], lo ha sido dentro de su competencia y en la forma que prescribe la ley;

Que, sin perjuicio de lo razonado y concluido, el Tribunal no puede menos que observar que, con la forma actual de distribución del tiempo de propaganda electoral gratuita [...], en la práctica se llega a ciertos casos a no poder ejercer realmente el derecho a comunicar ideas a la audiencia, como resultado de la excesiva brevedad de tiempo que se asigna a algunos partidos y a los candidatos independientes (cc. 12-3, énfasis agregado).

d) El voto de minoría

El Ministro Juica concurrió a la decisión del Tribunal, en una argumentación que se asemeja más a un voto disidente. Su argumentación puede presentarse de la siguiente manera:

(1) El Consejo Nacional de Televisión tiene un deber de "asegurar un trato mínimo equitativo entre los distintos candidatos". Dicho deber tiene por objeto el "que la población destinataria se ilustre adecuadamente de los postulantes al Congreso Nacional, sean éstos militantes de partidos políticos o independientes" (v. min);

(2) Dicho deber se funda en las siguientes normas legales y constitucionales: el artículo $1^{\circ}$ de la Ley 18.838, según el cual corresponderá al Consejo "velar por el correcto funcionamiento de los servicios de televisión" (inc. $2^{\circ}$ ), lo que debe entenderse como

el permanente respeto, a través de su programación, a los valores morales y culturales propios de la Nación; a la dignidad de las personas; a la protección de la familia; al pluralismo; a la democracia; a la paz; a la protección del medio ambiente, y a la formación espiritual e intelectual de la niñez y la juventud dentro de dicho marco valórico (inc. 3); 
El artículo 14 de la misma ley, que establece el principio del pluralismo, señalando:

El Consejo deberá adoptar medidas y procedimientos a fin de asegurar que en los programas de opinión y de debate político que se emitan por cualquier canal de televisión, se respete debidamente el principio del pluralismo (artículo introducido por la Ley 19.131);

Por último, el artículo 18 de la Constitución, que establece un deber para el legislador de dar un trato igual a los candidatos independientes frente a los partidos políticos;

(3) Cuando el Consejo fija el tiempo de propaganda electoral para los partidos que no participaron en la elección anterior y para los independientes en un segundo,

excede con mucho el criterio y prudencia que es menester considerar a fin de que los independientes puedan, dentro del trato igualitario y de observancia al principio de pluralismo político, exponer las ideas que justifiquen, ante la opinión pública, su programa político (v. min);

(4) El Consejo debería, para no incurrir en una infracción al principio del pluralismo, fijar "un mínimo aceptable para estos fines". El mínimo aceptable, en opinión del Ministro Juica no puede ser inferior a veinte segundos para cualquier candidato.

\section{e) Consideraciones previas y programa de desarrollo}

El fallo del Tribunal y el voto de minoría del Ministro Juica plantean dos cuestiones diferentes. Al mismo tiempo que el Ministro Juica insiste en considerar que los principios constitucionales y legales exigían del Consejo una solución distinta del asunto, el voto de mayoría se muestra escéptico frente a la posibilidad de extender su competencia hacia la aplicación de dichos principios, pese a considerar que hay un derecho afectado por la medida.

En primer lugar, debe analizarse la decisión del Tribunal, que considera que si bien la decisión es injusta, es la decisión jurídicamente correcta. Una vez que se haya aclarado en qué consiste la posición del Tribunal puede volverse la mirada hacia la decisión concreta del Consejo y a la propuesta del Ministro Juica, en relación a la solución del problema sustantivo que plantea la distribución del tiempo en el franja electoral.

\section{LA COMPETENCIA DEL TRIBUNAL Y LA APLICACIÓN DE LA CONSTITUCIÓN}

El Tribunal en su voto de mayoría consideró que la resolución del Consejo se ajustaba a la ley. El Tribunal señaló que el Consejo había actuado dentro de su competencia y que había aplicado correctamente la ley. Sin embargo, luego observó que la resolución encerraba algún grado de injusticia al afectar un legítimo derecho del reclamante. 
No se puede aseverar categóricamente qué significa la observación del Tribunal. Puede que se dirija contra la disposición legal que establece los criterios que el Consejo debe seguir. En ese caso la consideración del Tribunal dejaría ver su posición respecto a la competencia del Consejo, que se entiende limitada a ejecutar la ley, dirigiéndose la crítica hacia el incorrecto ejercicio de la potestad legislativa. Por otro lado, podría ser que dicha observación se dirija a la interpretación que el Consejo realizó de dicha disposición. En esta segunda hipótesis el Tribunal habría considerado que el tribunal ejecutó incorrectamente la ley, no obstante a actuar dentro de su competencia. Esta alternativa parece no tener cabida si se nota que el Tribunal consideró que el Consejo distribuyó el tiempo "en la forma que prescribe la ley".

Más allá de la ambigüedad que la exigua argumentación de la solución del Tribunal, es inequívoco que éste comprende que, tanto el propio Tribunal como el Consejo, están limitados por la distribución de competencias constitucionales. Mientras el Consejo resuelva conforme a la ley que dicha resolución produzca un resultado inconstitucional no puede dar pie a la intervención del Tribunal. Presentado de otra manera, el Tribunal resuelve la pregunta sobre cómo se determina qué pasa cuando la aplicación de la ley requiere un resultado inconstitucional. En ese caso, ¿el Consejo debe desatender la ley, para satisfacer las exigencias de la Constitución?, o, por el contrario, ¿no puede cuestionar la constitucionalidad de la ley, dado que esa labor está entregada en nuestro sistema jurídico de manera excluyente al Tribunal Constitucional? Esa tensión entre la fuerza normativa de la Constitución y la distribución de competencias, y en eso el Tribunal no se equivoca, sin duda debe ser resuelta a favor de la distribución de competencias, únicamente de esa manera se puede cautelar realmente la supremacía de la Constitución. ${ }^{2}$

Pero el fallo del Tribunal parece decir algo más. El fallo del Tribunal parece entender que el Consejo no pudo actuar de otro modo, que la ley no le daba espacio para resolver de otra manera. La determinación de si el Consejo cuenta efectivamente con algún espacio de discreción dentro del ejercicio de su potestad, o si, por el contrario, se trata de una potestad totalmente reglada, no es algo que el Tribunal dejara entrever. Sin embargo, la determinación de si se trata de una de una potestad de una u otra clase parece decisiva a la hora de concluir si el Consejo actuó debidamente. Si es posible justificar que el Consejo podría haber actuado de otro modo, respetando la distribución de competencias y al mismo tiempo presentando una resolución que no pugnara con los principios constitucionales invocados, entonces podría sostenerse: esa era la resolución que la fuerza normativa de la Constitución exigía. En este sentido, la idea de la fuerza o eficacia normativa de la Constitución es susceptible de diversas hipótesis, la más plausible de las cuales exige de parte del órgano aplicador o ejecutor de la ley una interpretación conforme a la Constitución. ${ }^{3}$

2 vide Marshall, P. E., "Inaplicabilidad por inconstitucionalidad”, en Revista de Derecho, UAI, No 2 , 2005 , p. 808.

3 vide Marshall, P. E., "El efecto horizontal de los derechos fundamentales y la primacía de la distribución de competencias jurisdiccionales frente al principio de supremacía constitucional”, en Revista de Estudios de la Justicia, No 11, 2008 (en prensa). 
El voto de minoría del Ministro Juica apuntaba a una dirección correcta al sostener que existe una infracción a un deber por parte del Consejo en la adopción de un sistema de distribución como el adoptado. Sin embargo, para determinar si el Consejo efectivamente infringe un deber, primero debe determinarse en qué consiste ese deber. A continuación, se presentará una visión de lo que la Constitución y sus principios exigen para el caso, después de lo cual podrá esclarecerse cuál era el deber que existía para el Consejo.

\section{LO QUE La CONSTITUCión EXIGE}

La Constitución es la norma fundamental del ordenamiento jurídico. Junto con ello, la Constitución es también el acto mediante el cual un conjunto de personas establece una comunidad política. Las constituciones modernas se caracterizan materialmente por consagrar dos principios fundamentales, de los cuales puede entenderse que el resto del contenido de la Constitución no es más que su desarrollo. Estos son el principio de la democracia, como forma de organización del poder político (art. $4 \mathrm{CPol}$ ) y el principio de la protección de los derechos fundamentales, como forma de control del poder político organizado (arts. 5 y $19 \mathrm{CPol}$ ).

Suele afirmarse que la democracia es la única forma legítima de toma de las decisiones políticas en el Estado moderno. El principio de la democracia exige que la toma de las decisiones del Estado esté, en definitiva, en manos del pueblo. En la medida que una norma jurídica tiende a dificultar o a impedir que el pueblo decida o controle las decisiones del Estado, debe considerarse que existe una tensión o afectación del principio. Muchas veces, claro, se establecen reglas que restringen el poder del pueblo sobre las decisiones, esas normas pueden estar más o menos justificadas. En la medida que dichas normas se puedan justificar en la protección de derechos fundamentales o en la protección del propio principio democrático, su establecimiento no será conflictivo a la luz de la Constitución. ${ }^{4}$

De estas ideas tan abstractas es difícil concluir qué es lo que exige la Constitución a propósito de la propaganda electoral y más específicamente sobre la distribución del tiempo en la franja electoral. Sin embargo, pueden encontrarse principios más desarrollados establecidos en la propia Constitución, mediante los cuales pueden construirse razonamientos tendientes a concretar las exigencias que el principio de la democracia plantea, en una dirección que arroje luz al problema que se trata.

\section{a) El principio de igual tratamiento}

El principio de igualdad es uno de los principios de justicia política que están en la base universal de la organización de la comunidad política occidental. Por eso es un

${ }^{4}$ vide Böckenförde, E. W., "La democracia como principio constitucional", en Estudios sobre el Estado de Derecho y la Democracia, Ed. Trotta, Madrid, 2000, pp. 57 ss. 
principio que recorre toda la Constitución Política, adoptando diversas formas y modelando diversas instituciones. El principio de igualdad, como principio constitucional, exige la igualdad de trato por parte del Estado frente a quienes se encuentren en iguales condiciones. El principio de igualdad democrática, que se refiere a la posición de los ciudadanos frente a la toma de las decisiones políticas, tiene importancia medular y es el principio rector de todas las instituciones electorales. La igual consideración de los ciudadanos en pos de la configuración de la voluntad general exige la exclusión, por razones de principio, de cualquier graduación o diferenciación entre ellos, de acuerdo a cualquier característica no justificada suficientemente. ${ }^{5}$

Particularmente, en relación a la igualdad democrática, la Constitución desarrolla el principio de igualdad entre partidos políticos e independientes (art. 18 CPol). ${ }^{6}$ Dicho principio exige un igual tratamiento, que consiste en que los independientes tienen que tener las mismas dificultades y facilidades de cara a las elecciones que los candidatos representantes de los partidos. Sin embargo, el principio de igual tratamiento no hace referencia a la igualación entre partidos y candidatos, sino que se reduce a exigir el mismo tratamiento para todos los candidatos, sean estos independientes o afiliados. Esa interpretación se basa tanto en el tenor literal de la disposición como en el rol de los partidos políticos en el sistema constitucional.

El Tribunal Constitucional, sin embargo, en su importante sentencia de la causa Rol 53 de 1988 (cc. 12-7) y en su más reciente sentencia de la causa Rol 301 de 1999 (cc. 7-14), sostiene una interpretación extensiva del mandato constitucional de igualdad de trato. El Tribunal señala que la Constitución exige una igualdad sustancialmente más estricta que la que aquí se sostendrá que la Constitución exige. Con todo, el Tribunal no da mayores razones que justifiquen la posición que adopta, por lo que no se revisará su posición.

Para esclarecer el alcance del principio de igual tratamiento, primero debe aclararse cuál es el rol de los partidos políticos en el sistema constitucional. Luego, podrá observarse que la posición de los independientes es cualitativamente distinta. Por último, podrá ilustrarse mediante una distinción conceptual entre elección particular y elección general, el alcance restringido del principio.

(1) El rol constitucional de los partidos políticos. La democracia representativa es la única forma realizable de democracia. ${ }^{7}$ Los partidos políticos se vuelven relevantes (son pieza fundamental) cuando nos situamos en el contexto de una democracia representa-

\section{${ }^{5}$ Ibid 84.}

${ }^{6}$ Llama la atención la falta de tratamiento dogmático de esta disposición constitucional, vide Silva, A: Tratado de Derecho Constitucional, Ed. Jurídica de Chile, Santiago, 1997, t. iv, p. 279; Verdugo, M., E. Pfeffer y H. Nogueira, Derecho Constitucional, Ed. Jurídica de Chile, Santiago, 1999, t. i, p. 164; Cea, J. L., Derecho Constitucional Chileno Ed. Universidad Católica de Chile, Santiago: 2002, t. i, p. 346-8; Vivanco, A., Curso de Derecho Constitucional, Ed. Universidad Católica de Chile, Santiago, 2004, t. ii, p. 206; García, A. M., Ley Orgánica Constitucional de Partidos Políticos, Ed. Jurídica de Chile, Santiago, 1988, p. 28.

7 vide Böckenförde, E. W., "Democracia y representación. Crítica a la discusión actual sobre la democracia”, en Estudios sobre el Estado de Derecho y la Democracia, Ed. Trotta, Madrid, 2000, pp. 133-143. 
tiva. Esa categoría la adquieren en la medida que se transforman en el instrumento de mediación entre las voluntades de los individuos que integran el pueblo y su voluntad general (del pueblo). Los partidos políticos son los únicos agentes políticos que son capaces de articular discursos públicos que incorporen los intereses de los individuos y grupos, pero que al mismo tiempo contengan el momento normativo dirigido por el "espíritu del pueblo" que es capaz de dar vida a la ficción de la voluntad general. Esa labor provee de la racionalidad intrínseca al discurso estratégico a la actividad del Estado y también permite que el Estado desarrolle un plan de acción que no se traduzca en mera complacencia, sino en la persecución del verdadero interés de la comunidad política. ${ }^{8}$ Un gobierno coherente no sólo es deseable desde el punto de vista del orden y seguridad, sino que se erige como finalidad de proceso de selección de un gobierno como alternativa a otro gobierno.

(2) Consecuencias del rol constitucional de los partidos politicos. En el derecho constitucional moderno, los partidos políticos son el objeto de numerosas prerrogativas de las que carecen los candidatos independientes. Sin embargo, también son objeto de derechos y obligaciones que muchas veces restringen su ámbito de acción. Por ejemplo, los partidos políticos deben contar con órganos constituidos, deben sujetar su gobierno interno al principio de la democracia, deben contar con una declaración de principios y no infringir los límites establecidos en los artículos 19 n 15 y 23 de la Constitución Política. Por último, casi todos los actos de los partidos políticos son públicos. Ello tiene su fundamento en que la Constitución entiende que son los partidos políticos y no los independientes los que pueden canalizar la legitimidad del pueblo hacia el gobierno y sus órganos. Por tanto, la Constitución confía a los partidos políticos las herramientas para la participación política, incluida la participación electoral.

(3) Los independientes frente a los partidos. Como contrapartida, la Constitución desconfía de la capacidad de participación política eficaz de los individuos aislados. Un ciudadano independiente carece de un programa político de gobierno, de unos principios y directrices. Justamente esto es lo que une bajo un partido político a otros ciudadanos. Los independientes pueden concitar un gran apoyo popular, pero dicho apoyo no se deberá a la preferencia del pueblo por su programa político, sino a su carisma o liderazgo. Si bien el principio carismático es un principio reconocido por los sistemas presidencialistas como el chileno, su vigencia no abarca la elección de los parlamentarios, elección que se funda en el principio de representación, representación que únicamente es posible a través de la mediación de los partidos. Dicha representación solamente es posible si quien ejerce el cargo de elección popular tiene un programa de gobierno para todo el pueblo. Eso es de lo que carecen los candidatos independientes. El principio de representación como supuesto de la legítima distinción entre partidos políticos e independientes queda expresado en el artículo 51 de la Constitución, según el cual se completará la vacante

${ }^{8}$ Ibíd. 147 ss. El rol constitucional de los partidos políticos es erosionado normalmente por la autonomización de los partidos respecto al pueblo y por la complacencia vacía que pueden mostrar frente a la opinión pública. Ambos son problemas contingentes y que no afectan al rol constitucional de los partidos políticos necesariamente. 
originada por un miembro de un partido político con otro miembro del mismo partido (inc. 3). Por otro lado, se establece que los parlamentarios elegidos como independientes no serán reemplazados (inc. 4).

(4) La elección general y la elección particular. La elección parlamentaria es una elección doble. Ello está dado fundamentalmente por el carácter colegiado del órgano que se elige. Es una elección en que junto con cada una de las elecciones particulares de cada distrito o circunscripción se está llevando a cabo la elección general del Congreso Nacional. Esa dualidad no está presente en la elección de los órganos unipersonales como el Presidente de la República o el Alcalde. La particularidad de la doble elección está en que el Congreso es el órgano representativo por excelencia. Dicha representación es del pueblo en su totalidad, esto quiere decir que cada diputado y senador no representa sino a todo el pueblo. Cuando un partido político se presenta a una elección parlamentaria, no obstante poder presentar candidatos sólo en determinadas localidades, su finalidad es lograr la representación del pueblo en su totalidad. Ello está avalado por el programa de gobierno y por el equipo de personas que respaldan el ejercicio del poder político del militante si éste es elegido. Cuando un independiente se presenta a una elección en una localidad, normalmente su pretensión será la de representar a dicha localidad, como caudillo o líder. Si dicho caudillo o líder, además, cuenta con un plan de gobierno y un equipo de personas que lo auxiliarán, todavía le faltará el ánimo conseguir para sí el poder hegemónico del Estado. Si cuenta con dicho ánimo, se convertirá en el líder carismático de un partido político, el cual deberá regularse por los principios y normas acuñados para dichas agencias. Sin embargo, no es común el surgimiento de dicho tipo de partidos personalistas. Y en la medida que un independiente sea sólo un independiente, no puede reclamar para sí los beneficios que están previstos para quienes quieren servir (o guiar) al pueblo en su totalidad, sino los beneficios que están previstos para quienes quieren servir a una parte del pueblo. Será razonable que la ley no otorgue a dichos independientes las facilidades y prerrogativas que sí otorga a los partidos. En particular, los recursos electorales asignados a un candidato independiente a parlamentario deberán calcularse sobre la base de universo electoral que él aspira a representar, no sobre la base de todo el electorado. ${ }^{9}$

(5) El verdadero alcance del principio de igual tratamiento a la luz de la distinción elección general/particular. El principio de igual tratamiento exige, para dar un tratamiento desigual a los diversos candidatos, una argumentación satisfactoriamente razonable. En principio, no debería haber diferencia alguna en el tratamiento que la ley da a los candidatos, y así es, por ejemplo, en el caso de la franja presidencial, donde la ley señala que el tiempo de ésta se repartirá entre todos los candidatos en tiempos iguales. Sin embargo, como se sostuvo en un principio, el principio de igual tratamiento no exige igualdad entre candidatos independientes y partidos, sino solamente entre candidatos. Con ello lo que

${ }^{9}$ En la elección presidencial la cosa es muy distinta. Esta es una elección donde la Constitución sí admite el principio carismático, además de ser una elección en la cual incluso los candidatos independientes aspiran a representar al pueblo en su totalidad. 
se concluye es que no pueden haber discriminaciones injustificadas, especialmente en lo que respecta a la presentación de candidaturas como a la participación de los candidatos independientes en los comicios. Pero con base en la argumentación anterior, la repartición de los recursos electorales hecha de manera diferenciada, en razón del rol constitucional de los partidos políticos, no incumple el mandato constitucional del artículo 18.

\section{d) El principio de pluralismo político}

La explicación que antecede intenta justificar la distribución diferenciada que la ley hace de los recursos de la franja electoral entre candidatos independientes y partidos políticos. Pero ella no dice nada todavía para justificar la regla de proporcionalidad como criterio de distribución de recursos entre los partidos, cualquiera haya sido su votación en la elección anterior. Esto puede presentar problemas bajo otro de los principios que la Constitución establece expresamente: el principio de pluralismo político (art. $19 \mathrm{n}^{\circ} 5$ inc. $6^{\circ}$ ). La Constitución considera que todos los grupos y tendencias políticas pueden buscar hacerse del gobierno. El Estado no sólo debe abstenerse de interferir, sino que en virtud del principio de promoción de los derechos fundamentales (art. 5 inc. $2^{\circ} \mathrm{CPol}$ ), debe favorecer la mayor y más diversa expresión y representación política, así como la libre constitución y desarrollo de grupos y partidos políticos. Puede pensarse que, en virtud de este principio, toda medida estatal que tienda a limitar las posibilidades de cualquier grupo partido o candidato de competir en una elección (general), será en principio contraria al pluralismo político. ¿Es la distribución proporcional del tiempo de la franja contraria al pluralismo político? Lo será en la medida que atente contra las posibilidades de expresarse de los partidos y candidatos desfavorecidos. En definitiva, al impedirles competir en igualdad de oportunidades ante rivales injustamente beneficiados (art. $19 \mathrm{n}^{\circ} 2 \mathrm{CPol}$ ). Debe tomarse en especial consideración, como sostenía el Ministro Juica en su voto de minoría, que el valor de la propaganda electoral como instrumento político reside en la posibilidad de expresión y articulación de un discurso político.

\section{e) El derecho a la libre expresión}

Por último, se muestra especialmente relevante en este problema el derecho fundamental a la libertad de expresión (art. $19 \mathrm{n}^{\circ} 12 \mathrm{CPol}$ ). Dicho derecho es mencionado por el propio Tribunal Calificador de Elecciones en su voto de mayoría, como el derecho afectado por la regulación que se hizo de la distribución del tiempo de la franja. La opinión de que la libertad de expresión es uno de los derechos fundamentales que tienen directa relación con la democracia y con la participación política es universal y poderosa. ${ }^{10} \mathrm{La}$ posibilidad de un ejercicio real de la libertad de expresión y, más allá, la obligación del Estado de velar para establecer un régimen de igualdad de oportunidades para expresarse, son ideas que son admitidas en general en el derecho comparado y en el derecho

\footnotetext{
${ }^{10}$ vide Fiss, O., Libertad de Expresión y Estructura Social, Ed. Fontamara, México, 1997.
} 
internacional de los derecho humanos. ${ }^{11}$ Respecto a la distribución del tiempo en la franja electoral, queda por definir hasta dónde llega el deber del Estado, pero sin duda este es un supuesto de aquellos que cualquier análisis del rol como interés colectivo de la libre expresión debe tener en cuenta.

Resumiendo, puede sostenerse que si bien los principios constitucionales analizados no concluyen que una distribución proporcional del tiempo de la franja es sustantivamente inconstitucional, sí se puede argumentar que la Constitución exige que los independientes sean tratados en cada elección particular como iguales a otros candidatos con filiación política. También puede argumentarse que el Estado debe propiciar un estado de cosas en que los partidos tengan oportunidad de expresarse libremente y de luchar de manera efectiva (no sólo virtualmente) por hacerse del poder político. Dicho deber no sólo recae en el Poder Legislativo o el Ejecutivo, sino que, en virtud del artículo $6^{\circ}$ de la Constitución Política, en todos los órganos del Estado, incluido el Consejo Nacional de Televisión y el Tribunal Calificador de Elecciones.

\section{De vuelta al caso}

Una vez aclarado que existe una exigencia material de parte de la Constitución, en un sentido que tanto el voto de mayoría como el voto de minoría del fallo toman en cuenta, se puede volver a poner atención en los aspectos del caso y volver a cuestionar si el Consejo pudo actuar de otra manera.

\section{a) El tenor de la ley y el sistema del Consejo}

El sistema legal de distribución de tiempo para la elección parlamentaria antes expuesto, consta de tres tipos de reglas: a) una regla de distribución proporcional: entre partidos antiguos; b) dos reglas de equivalencia: partidos nuevos e independientes en su conjunto se asimilan para los efectos de la distribución del tiempo al partido antiguo menos votado en la elección anterior, y c) regla de distribución igualitaria: del tiempo asignado en conjunto entre los candidatos independientes. El sistema legal de distribución establece, mediante las reglas señaladas en relación al tiempo determinado para la franja, una fórmula bastante rígida de distribución.

Teniendo a la vista los resultados de la elección anterior y aplicando las reglas establecidas en la ley, el cálculo que el Consejo debió realizar arroja necesariamente un porcentaje del tiempo correspondiente a cada partido o candidato. En el caso en análisis, el Consejo consideró un universo de votos que excluyó los votos blancos y nulos, excluyó también los recibidos por partidos que no se presentan en la elección en curso

${ }^{11}$ Para un análisis de la jurisprudencia internacional, vide Fuentes, X., "La protección de la libertad de expresión en el sistema interamericano de derechos humanos y la promoción de la democracia”, en Revista de Derecho, Universidad Austral de Chile, vol. XIII, 2002, y Fernández, F., "La libertad de expresión en la doctrina del Tribunal Europeo de Derecho Humanos”, en Revista de Estudios Políticos (Nueva Época), No 70, 1990. 
y los recibidos por los candidatos independientes. Con ese universo correspondiente al $79,53 \%$ del total de votos emitidos, determinó cuál era el porcentaje que correspondía a cada partido y candidato en la franja electoral. En el caso del Partido Liberal, que obtuvo el $0,05 \%$ de los votos en la elección parlamentaria anterior y, por tanto, fue el partido menos votado, el porcentaje correspondiente fue de $0,063 \%$ del tiempo de la franja. Las reglas de equivalencia hacen extensivo ese porcentaje a los independientes en su conjunto y a los partidos nuevos. Por último, una regla de igual distribución dividirá ese $0,063 \%$ entre el número de los candidatos independientes.

La ley no sólo fija reglas de distribución sino también el tiempo de duración de la franja electoral, que en este caso fue de 20 minutos. Sin embargo, la ley no fija lo que el Ministro Juica llamó un "mínimo aceptable" de tiempo por candidato o partido, sino que se limita a establecer reglas de equivalencia y una regla general de proporcionalidad. La resolución del Consejo presenta un sistema que fija el mínimo asignable en un segundo. Si seguimos estrictamente la regla de la proporcionalidad, el tiempo asignado debería ser de 0,756 segundos. La pregunta consiguiente es: ¿por qué el Consejo fijó un mínimo si ello no era exigido por la ley? La respuesta desde una perspectiva formal es que el Consejo ejerció su competencia para fijar la distribución, en la que debía, de alguna manera, racionalizar la distribución del tiempo de la franja. Un segundo como unidad mínima de distribución parecía razonable. Pero frente a esa conclusión surge una nueva pregunta: ¿por qué el mínimo fue de un segundo? ¿Por qué no fue de medio segundo o de diez segundos? La respuesta debería ser que el Consejo tiene un margen de discreción para ejercer su potestad de ejecución de la ley y su Acuerdo es un legítimo ejercicio de dicha potestad. La única respuesta que queda para justificar que el Consejo haya fijado una alteración a la regla de la estricta proporcionalidad es que el Consejo tenía un margen de discrecionalidad en la resolución de la distribución del tiempo de la franja.

El sistema diseñado por el Consejo para la distribución del tiempo de la franja no respeta estrictamente el mandato de proporcionalidad del artículo 31 de la Ley 18.700. Por otro lado, tampoco parece que el tiempo asignado a los candidatos independientes (un segundo distribuido entre todos ellos) les permita enfrentar la elección particular a la que se enfrentan a otros candidatos en términos de igualdad y ejerciendo su derecho a expresar su programa político. Por último, el mínimo de un segundo no parece permitir a los partidos políticos nuevos enfrentar la lucha por el poder político en igualdad de condiciones. El sistema del Consejo vulnera el principio de estricta proporcionalidad establecido en la ley y su sistema de distribución no es compatible, al menos aparentemente, con los principios constitucionales analizados, los que en virtud de las normas legales citadas por el voto de minoría arriba expuesto obligaban al Consejo Nacional de Televisión a la hora de tomar su determinación.

La pregunta que cabe hacer a continuación es si es necesario torcer el tenor de la ley para obtener un resultado constitucionalmente aceptable. 


\section{b) Las alternativas interpretativas y la interpretación correcta de la ley}

El primer sistema alternativo de distribución que puede presentarse es un sistema que no tenga un "mínimo aceptable". Un sistema que siga fielmente el principio de distribución proporcional del tiempo de la franja no puede fijar ese mínimo. En ese sistema, el tiempo asignado a cada nuevo partido sería de 0,756 segundos, los mismos que se distribuirían entre los candidatos independientes. Este sistema no se diferencia de manera relevante del sistema del Consejo en lo que respecta a su conformidad con los principios de igualdad y pluralismo. Un segundo sistema es el que plantea el Ministro Juica. Un sistema con un mínimo aceptable mayor. Ese mínimo aceptable de diez segundos establecería una mayor coherencia con los principios de igualdad y pluralismo, pero traería más problemas con la regla de proporcionalidad que los que ya acarrea el sistema del Consejo.

Un sistema jurídicamente correcto no necesita infringir la regla de proporcionalidad para estar conforme a los principios constitucionales. La regla de proporcionalidad es una regla que no debe romperse. Lo que exigen los principios constitucionales atingentes al caso es una mejor interpretación de la regla, una interpretación que dé cuenta de los principios que están en la base del ordenamiento jurídico del cual la regla del artículo 31 de la Ley 18.700 es parte. La forma de llegar a ese sistema se basa en la consideración de la totalidad de la franja electoral, a través de todo el periodo de propaganda, como una unidad de distribución. La ley establece claramente el porcentaje de tiempo de franja que corresponde a cada partido y candidato, pero no señala cómo ese porcentaje ha de distribuirse en forma temporal. Es perfectamente posible que el objetivo pretendido por el recurrente de contar con una secuencia de segundos o minutos más extensa que la que se le otorga, se logre, en la medida que se omita su participación en algunas emisiones de la franja, aumentándose otras. Con esto, los partidos nuevos, y tal vez los independientes, podrán expresar un discurso articulado y de más contenido, siendo preferible esto, que aparecer sólo como imágenes repentinas a los ojos de los electores, y no poder "exponer las ideas que justifiquen, ante la opinión pública, su programa político" (v. min). El que una distribución tal pueda ser posible dependerá de la justificación de que el ejercicio de la potestad del Consejo tiene un margen de discrecionalidad y que ésta no infringe el tenor de la ley.

Queda por ver cuál será la forma en que el Consejo fije la distribución del tiempo de la próxima franja electoral.

\section{BIBLIOGRAFÍA}

Böckenförde, E. W., “Democracia y representación. Crítica a la discusión actual sobre la democracia”, en Estudios sobre el Estado de Derecho y la Democracia, Ed. Trotta, Madrid, 2000.

BöCKENFÖRDE, E. W., "La democracia como principio constitucional", en Estudios sobre el Estado de Derecho y la Democracia, Ed. Trotta, Madrid, 2000. 
CeA, J.L., Derecho Constitucional Chileno, Ed. Universidad Católica de Chile, Santiago, 2002.

División Jurídico-Legislativa del Ministerio Secretaría General de la Presidencia, Doctrina Constitucional del Presidente Frei Ruiz-Tagle, Santiago, 2000.

FERnÁnDEZ, F., "La libertad de expresión en la doctrina del Tribunal Europeo de Derecho Humanos”, en Revista de Estudios Políticos (Nueva Época), No 70, 1990.

FIss, O., Libertad de Expresión y Estructura Social, Ed. Fontamara, México, 1997.

Fuentes, X., "La protección de la libertad de expresión en el sistema interamericano de derechos humanos y la promoción de la democracia", en Revista de Derecho, Universidad Austral de Chile, vol. XIII, 2002.

García, A. M., Ley Orgánica Constitucional de Partidos Políticos, Ed. Jurídica de Chile, Santiago, 1988.

Marshall, P. E., "Inaplicabilidad por inconstitucionalidad", en 2 Revista de Derecho, UAI, 2005.

Marshall, P. E., "El efecto horizontal de los derechos fundamentales y la primacía de la distribución de competencias jurisdiccionales frente al principio de supremacía constitucional", en Revista de Estudios de la Justicia, No 11, 2008 (en prensa).

Silva, A., Tratado de Derecho Constitucional, Ed. Jurídica de Chile, Santiago, 1997.

Verdugo, M; E. Pfeffer y H. Nogueira, Derecho Constitucional, Ed. Jurídica de Chile, Santiago, 1999.

Vivanco, A., Curso de Derecho Constitucional, Ed. Universidad Católica de Chile, Santiago, 2002. 